\title{
LA IMPRONTA JACOBINA DEL LIBERALISMO RADICAL EN ANDALUCÍA (1820-1873). UNA APROXIMACIÓN DESDE LA SOCIABILIDAD POLÍTICA.
}

\author{
DIEGO CARO CANCELA \\ Universidad de Cádiz
}

En 1989, Jacques Maurice, en unas interesantes «Propuestas para una historia de la sociabilidad en la España contemporánea» (1), se lamentaba de la escasa propensión de los historiadores españoles a utilizar esta categoría historiográfica (2), plenamente incorporada ya, hacía tiempo, en países como Francia, Italia o Alemania, desde que se publicaran los trabajos pioneros de Maurice Agulhon (3). Tres años después, en 1992, Jordi Canal tampoco presentaba un balance más alentador:

«Salvo en el caso de los estudios antropológicos, con un par de grupos bien definidos en Andalucía y el País Valenciano, y en el de los historiadores hispanistas franceses, no existen más núcleos consolidados de estudio de la sociabilidad en la España contemporánea» (4).

En el caso de Andalucía, a pesar de contarse con el trabajo pionero de Antonio Miguel Bernal y Jacques Lacroix, aparecido en 1975 y dedicado a las asociaciones y casinos sevillanos (5), el análisis de la sociabilidad ha preocupado más al grupo de antropólogos de la Universidad de Sevilla, que ha liderado Isidoro Navarro y que ha centrado sus investigaciones en el tiempo presente (6), que a los propios historiadores, que hasta ahora apenas sí se habían interesado por esta parcela de nuestro más reciente pasado. Sólo Manuel Morales, desde la Universidad de Málaga, ha venido en los últimos años ocupándose de estas cuestiones, desde la dirección del Grupo de Investigaciones Históricas sobre la Sociabilidad Contemporánea (G.R.I.S.A.C.) y del proyecto titulado «La sociabilidad meridional. Prácticas culturales y formas asociativas (1840-1977)» (7) del P.A.I. (Plan Andaluz de Investigación). Y poco más.

Con este escaso bagaje previo, el presente trabajo -centrado en la sociabilidad política de la Andalucía decimonónica-, debe entenderse como una aportación más a un aspecto de la historia política apenas tratado y necesitado de nuevas aportaciones que superen el estrecho y tradicional marco de la trilogía "partidos-líderes-elecciones», para volcarse en parcelas todavía inéditas, como las formas cotidianas de «hacer política», los medios de difusión e intercambio de ideologías o la propia infraestructura material del local público o de agitación.

Tomando como espacio temporal los años que van de 1820, cuando comienza el Trienio Liberal, a 1873, y el fracaso de la Primera República, 
pretendemos demostrar a continuación el fuerte componente francófilo o jacobino que tiene la sociabilidad política que se practica en la Andalucía de este período, hasta el punto de poder afirmar, con toda contundencia y no sin un evidente riesgo, que la última aspiración de los liberales «exaltados» primero, los progresistas después y los republicanos, por último, fue hacer y culminar en España esa mítica -para ellos- Revolución que abrió en 1789 en Francia un nuevo período en la Historia de la Humanidad. Queremos, en definitiva, analizar cómo se manifiesta ese jacobinismo importado en el discurso y en las formas de organizar los espacios políticos, a la luz de las fuentes hoy disponibles.

$\mathrm{Y}$ es que ya desde sus primeros meses, unos acontecimientos de tanta trascendencia como los que estaban ocurriendo en el país vecino, no podían dejar de «contagiar» a España, más aún cuando fueron los propios «revolucionarios» los primeros interesados en propagar sus mensajes ideológicos en todas las direcciones, en busca de una solidaridad que le negaban las monarquías europeas del momento. Marcelin Defoumeaux (8), Richard Herrr (9), Gonzalo Anes (10) y Luis Miguel Enciso, para el caso concreto de Cádiz (11), han narrado cómo desde los primeros meses d ela Revolución llegaron a España folletos, panfletos y otros materiales, a través de la frontera y los puertos de mar, lo que llevó al Gobierno a recurrir a la Inquisición, con la intención de frenar la propagación de unas doctrinas que cuestionaban abiertamente los mismos cimientos del orden tradicional y de la monarquía absoluta. Sin mucho efecto, porque como le contaba el presbítero Pedro Estala en una carta, a su amigo Forner, fiscal en la audiencia de Sevilla, en tiempos de la guerra contra la Convención (1793-1795):

«Junto a Mariblanca, y en el café no se oye más que de batallas, revolución, convención, representación nacional, libertad, igualdad; hasta las putas te preguntan por Robespierre y Barère, y es preciso llevar una buena dosis de patrañas gacetales para complacer a la moza que se corteja» (12).

Pasados estos tiempos febriles de tratados, paces y guerras, los valores contenidos en la ideología revolucionaria, lejos de perderse, se mantendrían ocultos o públicos, en función de las coyunturas históricas, en aquellos grupos políticos que verdaderamente se sentían herederos de este legado. Las Cortes de Cádiz y la Constitución de 181.2 constituirían la primera demostración de hasta dónde había penetrado en las élites liberales los principales principios de constitucionalismo francés de 1791 y de sus intenciones de adaptar la obra de la Revolución a la realidad peninsular (13).

Los primeros espacios de sociabilidad política, estrictamente hablando, de la Andalucía contemporánea, son las Ilamadas Sociedades Patrióticas, que empiezan a surgir inmediatamente después del triunfo del pronunciamiento de Riego y la implantación del régimen liberal, en 1820. Su impronta francófila no pasó desapercibida para los protagonistas y testigos de aquellos agitados años. De esta manera, si el marqués de Miraflores las consideraba, «una copia servil de los clubs del año 1789 en Francia», Alcalá Galiano escribió, que tomaron 
como modelo a los' «meetings» o «debatings societies» de Inglaterra o a «los clubs malamente famosos de la Revolución de Francia» (14). Y es que estas Sociedades o Tertulias Patrióticas proliferan por casi todas las ciudades andaluzas en los primeros meses de 1820 , al calor de la efervescencia política que trae el Trienio Liberal y la recuperación de la Constitución de Cádiz. Se diferenciaban de anteriores foros de discusión como las Sociedades Económicas de Amigos del País -de las que algunas son herederas-en que sus actividades son eminentemente políticas. Más aún, de defensa y difusión de la ideología liberal, frente al ahora temporalmente derrotado pensamiento conservador absolutista.

Normalmente su nacimiento se produce en un establecimiento público, como un Café o una Academia, aunque más tarde cambiarían de centro de reunión, cuando la asistencia de público desborde el marco espacial de la primitiva sede. En un Café se creaba la Sociedad Patriótica de San Fernando, en el Salón Alto del Café del Rey Constitucional nacía la de Cádiz y en el Café del Turco, en plena calle Sierpes, se fundaba la de Sevilla, aunque pronto -esta última- trasladaría sus reuniones a un teatro, por no caber todos sus socios en lo que había sido un primer lugar de encuentro espontáneo de liberales. Esto mismo le ocurría a la Sociedad Patriótica de Córdoba, que de reunirse en el Café de Pepón, en el número seis de la calle Ambrosio de Morales, ante el rápido éxito de público-señoras incluidas- tuvo que trasladar sus debates también a un teatro, mientras que la de Málaga terminaría instalada en el convento de San Agustín (15).

El objetivo de estas Sociedades Patrióticas, a veces reguladas por un elemental reglamento (16), estaba más que claro. En palabras de la llamada Confederación Patriótica de Málaga, una de las primeras en fundarse de España (abril de 1820) se trataba de, «propagar las luces, extender los conocimientos útiles y promover la instrucción pública». $O$ dicho de otra forma: «la defensa de la Constitución, la vigilancia de los negocios públicos y la promoción de la instrucción», como establecía el reglamento de la primera Sociedad Patriótica de Cádiz (17).

Los medios empleados para alcanzar estos fines no podían ser más variopintos. El primero de todos, el debate, en el que intervenían tanto los socios, como invitados especiales, y después de los cuales, por votación, se producían los acuerdos. Previamente se había producido la lectura de los nombres de los socios, para ver quiénes eran los que tenían voz y voto en las deliberaciones y derecho a hacer uso de la biblioteca de la Sociedad Patriótica. Y el centro principal de estas sesiones era la exaltación de la Constitución, a través de acciones como: 1) la lectura diaria de un artículo de la misma en cada sesión que se celebraba (S.P. de Jerez), 2) la celebración de fiestas cívicas con motivo de la jura de la Constitución por el Rey, y 3) la colocación en las puertas de las casas de los vecinos de los artículos de la Constitución (acuerdo de la S.P. de Baena).

En esta tarea de difusión de los valores de la Constitución, el principal medio que van a emplear las Sociedades Patrióticas será la prensa, hasta el punto 
que una parte muy importante del primer periodismo político de estos años estuvo vinculado a la labor propagandística de estas Sociedades. La de San Fernando, por ejemplo, publicaba un periódico titulado «Sociedad liberal de la ciudad de San Fernando», la de Sevilla editaba la «Espada Sevillana contra Serviles» y de la Sociedad Patriótica de Vélez-Málaga era «El liberal moderado».

Pero las Sociedades Patrióticas tuvieron además la virtud de propagar, por primera vez, los principios del liberalismo político en el medio rural. Sólo así puede entenderse que pequeños municipios de la geografía andaluza (algunos todavía bajo el régimen señorial) tuvieran en estos años del Trienio sus propios espacios de sociabilidad política a través de estas Sociedades. Son los casos conocidos de las existentes en Tarifa y Trebujena, en la provincia de Cádiz, las de Lebrija, El Arahal o Cazalla en Sevilla, las de Albuñol o Baza en Granada y las de La Carlota, Cabra, Doña Mencía o Luque, en la provincia de Córdoba (18).

La restauración del absolutismo, con la invasión de los Cien Mil Hijos de San Luis en 1823, terminaría con estas experiencias de sociabilidad política y dejó reducida a las logias masónicas y las sociedades clandestinas la discusión y la propagación de los ideales liberales. Es el caso, por ejemplo, de la sociedad carbonaria Asamblea de Constitucionales Europeos, fundada en Cádiz en 1829, por un médico liberal exiliado en Gibraltar, junto con un comerciante que luego colaboraría con Mendizábal y de la que sólo conocemos el nombre (19). Sólo con la muerte de Fernando VII y la vuelta del régimen liberal se produce una reactivación de la sociabilidad política, reforzada por el regreso del exilio de las principales figuras de esta ideología (Alcalá Galiano, Istúriz y Mendizábal) y otros cientos de emigrados, que se plasma en la publicación de numerosos periódicos y la formación de nuevos «clubs» políticos por las principales ciudades del país, produciéndose -a partir de 1836-, la cristalización de los que serán los dos principales grupos políticos de la monarquía isabelina: el llamado partido estacionario o moderado y el progresista o exaltado (20).

Nuevamente reaparece la huella francófila, porque estos últimos van a ser definidos por Peter Janke como «los jacobinos de España» (21). De todas formas, estamos todavía ante los clásicos grupos políticos de «notables», defensores de un liberalismo oligárquico, sostenido en el sufragio restringido $o$ censatario. No existían agrupaciones partidarias más allá de la circunscripción electoral, la propaganda política se limitaba a la prensa y las únicas reuniones que había se producían en el teatro o casino local, sólo cuando se convocaban las elecciones y para elegir el correspondiente comité electoral.

Al margen de esta forma de «hacer política», de élites y notables de la monarquía de Isabel II, estaba el republicanismo decimonónico. Una ideología que no se quedaba sólo reducida a la defensa de una concreta forma de Estado, sino que entonces se suponía toda una alternativa política, basada en la democratización de la vida pública, la universalización del sufragio, la 
eliminación de los privilegios sociales y la laicización de la vida educativa y cultural (22). En dos grandes rasgos podemos resumir el universo ideológico de estos republicanos: populismo y jacobinismo (23). Y aunque Demetrio Castro define este último término como, «la herencia radical de la revolución liberal» (24), no existe un cuerpo doctrinal intangible que permita abarcar con claridad el significado del referido concepto. Jean Touchard, por ejemplo, escribe que, «el jacobinismo no es el mismo antes y después de la declaración de guerra, antes y después de la caída del rey, antes y después de la de los girondinos (y) antes y después de la de Robespierre» (25) y Albert Soboul llega incluso más lejos; estableciendo hasta cuatro tipos distintos de jacobinismos (26).

No obstante, tomando el rousseaunismo como base ideológica d elo jacobino, hay una serie de ideas y propuestas políticas, que claramente lo diferencian de otras corrientes coetáneas de la Francia revolucionaria (27). Estas son las que, con mayor o menor fidelidad se trasladan al pensamiento republicano español de mediados del siglo $\mathrm{XIX}$, mostrándose en toda su amplitud, en la eclosión periodística que se vive en los primeros meses del Sexenio Democrático de 1868: incorporación de las masas populares a la lucha por los derechos políticos y la igualdad, adopción de postulados intervencionistas en materia de consumo y empleo, difíciles de admitir por los sectores más ortodoxamente liberales, interés por el poder local o municipal y una retórica claramente anticlerical (28).

Parece evidente que en la transmisión y permanencia de esta ideología jacobina en España, junto a la prensa, el libro jugó un papel fundamental. Así se concluye del estudio de las bibliotecas privadas de la época, como ha podido demostrar María José Álvarez Pantoja, en la Sevilla de 1800 a 1868 (29) y que nosotros hemos comprobado también en el Jerez de estos mismos años. Efectivamente, el análisis del contenido de tres bibliotecas particulares, descrito de forma detallada e el inventario postmortem de sus propietarios, nos induce a la citada conclusión (30): la fuerte presencia de la cultura francesa, ya sea en literatura o ensayo.

En la biblioteca del marqués de Campo Real, por ejemplo, se encontraban las obras de Voltaire en 70 tomos, las de Rousseau en 25 y 8 tomos contenían el pensamiento de Montesquieu. Como puede deducirse, la Ilustración en pleno. Más heterogénea era la distribución de títulos de contenido francés de la biblioteca de Miguel de Giles. Tenía las «obras maestras» de Mirabeau, obras de Chateaubriand -25 tomos en rústica-, una «Historia de Francia» por Salas y Quiroga y las «Obras escogidas» de Napoleón. Pero de las tres, la que tenía un fondo más completo era la de Juan Piñero Ramos. No resultaba extraño, porque se trataba de una persona con gran significación en la vida política y cultural de Jerez, puesto que unía a su condición de miembro destacado del Partido Progresista local la de haber sido uno de los dos fundadores del periódico $E l$ Guadalete (31) y director del mismo hasta el año 1860. 
En su amplio catálogo de títulos sobre los más diversos temas, no faltaban los que tenían una directa relación con la Revolución Francesa. Así, en seis tomos estaba la «Revolución Francesa» de Thiers, «Las ideas napoleónicas», en un volumen; de Rousseau estaba su «Contrato social», amén de un diccionario de galicismo, un diccionario de francés-español y una gramática francesa.

Con esta notable presencia de la cultura revolucionaria en los hábitos lectores de la época, no podía extrañar la fuerte presencia de los conceptos y los valores jacobinos en la prensa demócrata jerezana, de los primeros meses del Sexenio. El 24 de septiembre de 1868 aparecía La Revolución, el 20 de octubre era $E l$ Club Democrático, con el inconfundible tema de «Libertad, Igualdad y Fraternidad» y, finalmente, el 10 de noviembre nacía El Club y la Revolución, producto de la fusión de las dos cabeceras anteriores.

A través de cualquiera de los tres, podemos acercarnos al jacobinismo presente en los republicanos andaluces. En este sentido, por ejemplo, como en los revolucionarios franceses, aquí, «la descalificación global de la monarquía no se limita a la institución en sí, sino que alcanza a las personas que la encarnan en un momento determinado» (32). Por este motivo, los demócratas jerezanos no sólo denostaban al régimen monárquico, sino también a la reina derrocada, Isabel II:

«Reina ingrata (...) eres el aborto de un sueño de Fernando, aquel Fernando que no soñaba sino en ahorcar a los que vendía; aquel Fernando que no se sonreía sino cuando pensaba en cometer una traición» (33).

Y frente a una monarquía que encarnaba todos los vicios y corrupciones, la República aparecía como la representación de la virtud y el gobierno perfecto, con argumentos, a veces, cercanos al utopismo (34). Esta visión idealizada del régimen republicano se acompañaba -en la mejor ortodoxia del jacobinismocon la exaltación de todo tipo de libertades y derechos. El propio periódico $E l$ Club Democrático ilustraba su cabecera son los siguientes temas:

\section{LIBERTAD IGUALDAD, FRATERNIDAD}

Libertad de cultos.- Libertad de enseñanza.- Libertad de reunión.- Libertad de asociación.- Libertad de industria.- Libertad de comercio.- Sufragio universal.- Sanción de las leyes por el Pueblo.- Institución del Jurado.- Derecho de libre defensa.- Derecho a la asistencia.- Derecho a la instrucción.- Derecho al trabajo.- Derecho a la propiedad (35).

Dentro de estos esquemas ideológicos, hay también una fuerte preocupación por la instrucción popular, fundamento, según estos republicanos, de toda regeneración moral (36). Para El Club Democrático, por ejemplo, la educación del pueblo era «necesaria e indispensable», porque la ignorancia era el principal sostén de «la tiranía del absolutismo»: 
«Interesa mucho a la causa de la libertad, fomentar las buenas lecturas, hasta en los pueblos de más corto vecindario, donde los buenos deben reunirse, asociarse, para leer 'en alta voz el periódico, el folleto, el libro que tienda a generalizar el conocimiento de los derechos del hombre y de sus deberes» (37).

En Málaga, este interés se traduce en la creación de una Asociación para la Enseñanza Popular, en 1869, con el objeto de elevar el nivel técnico y moral de las clases obreras y su formación política y social, alcanzando los 100 matriculados en noviembre de este mismo año y 300 tres meses después (38). En el Ayuntamiento republicano de Cádiz, además, estas preocupaciones educativas se combinaban con medidas de un claro sabor anticlerical. De esta manera, por ejemplo, el 25 de marzo de 1873, la Comisión municipal de Instrucción Pública acordaba suprimir «la enseñanza de toda religión positiva» de las escuelas costeadas por la Corporación (39). Y tres días después, acordaba cambiar los nombres de los colegios públicos de la ciudad, procedentes en su mayoría del santoral cristiano, por otros que definían principios morales universales, de claro sabor jacobino:

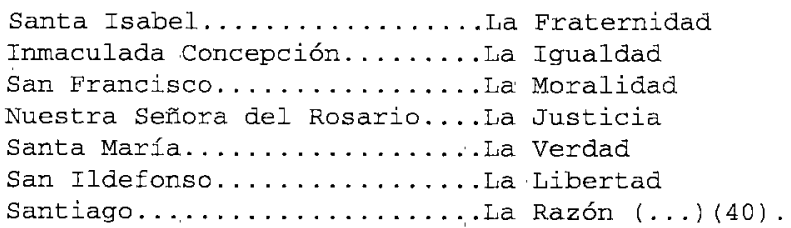

Pues bien, si estas «huellas» ideológicas no fueran ya de por sí demostrativas de las influencias del jacobinismo francés en la mentalidad política de los republicanos andaluces, estaban también los aspectos formales de su sociabilidad, quizá más reveladores todavía de todo lo que hasta ahora hemos escrito. Y es que igual que en la Francia revolucionaria (41), en estos primeros meses del sexenio, el centro de discusión política por antonomasia va a ser «el club», que va a desempeñar un papel fundamental en la expresión pública de la opinión republicana (42). Y si en Madrid y otras capitales de provincias, generalmente en estos clubs celebrarán sus reuniones en habitaciones alquiladas (43), en Jerez -igual que en Granada (44), Sevilla (45) y otras ciudades- los dos clubs democráticos que existían tenían sus sedes en sendos edificios religiosos clausurados, uno en el convento de la Victoria y el otro en la Iglesia de San Agustín. Una mesa formada por tres miembros del club presidían las asambleas, que se celebraban diariamente por la noche, en presencia de una numerosa asistencia (46) sometiéndose a discusión hasta los asuntos más triviales.

El sabor jacobino estaba presente, tanto en los nombres de los clubs, como era el caso de Málaga (47), como en el propio lenguaje que se emplea en los debates, luego recogidos en la prensa afín. El extracto que ofrecía $E l C l u b$ Democrático de Jerez, de la sesión celebrada el 23 de octubre, empezaba de la siguiente manera: 
«Se abrió la sesión a las siete y media bajo la presidencia del ciudadano Contrastin y asistencia a la mesa de los ciudadanos Ríos y Zambrano.

Usaron de la palabra los ciudadanos Ríos, Ruiz y Flictor; proponiendo este último el establecer una escuela para los hijos de los artesanos pobres, y concluyó ofreciendo sus servicios sin retribución de ninguna clase (...)

El ciudadano Revuelta (...) se extendió (sic) sobre la perfecta relación que existe entre la vida del hombre y la vida de los pueblos, y concluyó manifestando lo preciso del orden y armonía en los demócratas para conseguir la república federal» (48).

Y por si todavía no estaba clara esta admiración por el proceso revolucionario francés, en un artículo que se publicaba el 17 de octubre, en uno de estos periódicos, con el título de «Los clubs y los comités», se escribía:

«De los clubs salieron en Francia los grandes hombres que aceptaron gustosos las consecuencias de echarse sobre sí la enorme responsabilidad de luchar contra la teocracia (...). Allí se dieron a conocer los gigantes que con su poderoso aliento impulsaron las naves de la nación al puesto de la República.

De los clubs salieron Danton, Marat, Robespierre (...) y otros grandes revolucionarios (...). En los clubs se habla la palabra clara, franca e inteligible, que aprovecha el ciudadano trabajador, el artesano, el bracero (...). Los clubs son la cátedra del pueblo, donde se educa en política y de donde sale instruido (...)» (49).

Y un republicano federal de Sevilla, en las páginas del periódico madrileño La Justicia Social, escribía:

«...el club es para sus hijos la única expresión de las conquistas todas que el pueblo ha logrado con la revolución de Septiembre...en el club, sin temor, el pueblo se reúne; en el club, sin verse coartado el pueblo perora; en el club, sin ambages, ni rodeos, el pueblo se ocupa de la cosa pública...de sus aspiraciones, de sus esperanzas» $(50)$.

Con estos precedentes, cómo extrañarnos que los republicanos «intransigentes» -protagonistas del movimiento cantonal del verano de 1873-, le dieran a los órganos de poder local que crean, para sustituir a los derrocados Ayuntamientos, la denominación tan jacobina de Comités de Salud Pública. O que años después, Pi y Margall, uno de los grandes líderes del federalismo español, escribiera en su Historia de España en el siglo XIX,

«Conmovió al mundo de tal modo la Revolución Francesa que casi no es posible comenzar la historia de pueblo alguno de Europa en el siglo XIX, sin 
hacer referencia a aquel acontecimiento, el más grande sin duda de los de la época moderna» (51).

\section{NOTAS.}

(1) Publicadas en Estudios de Historia Social, $\mathrm{n}^{\circ}$ 50-51, 1989, pp. 133-143.

(2) Ibídem, p. 134.

(3) El primero sería La sociabilité meridionale. Confréries et associations en Provence orientale dans la deuxiéme moitié du XVIIIe siécle. 2 vols. Aix-enProvence, 1966. También: La République au village (París, 1970), 1848 ou l'apprentissage de la République, 1848-1852 (París, 1973) o Le cercle dans la France bourgeoise, 1810-1848. Etude d' une mutation de sociabilité (París, 1977), por citar otros trabajos. Define Agulhon la sociabilidad como «los sistemas de relaciones que enfrentan a los individuos entre ellos o les reúnen en grupos más o menos naturales, más o menos coactivos, más o menos numerosos».

(4) CANAL, Jordi: «La sociabilidad en los estudios de la España contemporánea», en Historia Contemporánea, $\mathrm{n}^{\circ} 7$, Universidad de País Vasco, 1992, p. 199.

(5) «Aspects de la sociabilité andalouse. Les associations sevillanes (XIXe.XXes.)», en Melanges de la Casa de Velázquez, vol. XI, 1975.

(6) De Isidoro Navarro son los dos trabajos fundamentales: Propiedad, clases sociales y hermandades en la Baja Andalucía. La estructura social de un pueblo del Aljarafe (Madrid, 1972) y Las hermandades andaluzas. Una aproximación desde la antropología (Sevilla, 1974). Más recientemente Javier ESCALERA ha publicado Sociabilidad y asociacionismo. Estudio de Antropología Social en el Aljarafe sevillano. Sevilla, 1990.

(7) Algunos trabajos suyos son «La sociabilidad popular en Málaga, 1840-1874: de la tutela burgues a la afirmación de una identidad diferenciada", en Estudios de Historia Social, $\mathrm{n}^{\circ}$ 50-51, 1989, pp. 243-271; «La Gloriosa en Málaga: del clamor revolucionario al fracaso de las expectativas populares», en Baetica, Universidad de Málaga, $\mathrm{n}^{\circ} 16,1994$, pp. 395-413, especialmente su apartado segundo titulado «Los clubs republicanos: nuevos espacios de sociabilidad política». También: «El asociacionismo ferroviario en el eje Alora-BobadillaAntequera (1904-1936)» en Revista de Estudios Antequeranos, $\mathrm{n}^{\circ} 2,1995, \mathrm{y}$ «Espacios y lugares abiertos en la sociabilidad andaluza del siglo XIX», en Actas del II Congreso de Historia de Andalucía. Andalucía Contemporánea. Córdoba, 1996. 
(8) Inquisición y censura de libros en la España del siglo XVIII, Madrid, 1973, pp. 107-216.

(9) España y la revolución del siglo XVIII. Madrid, 1988 (reedición), pp. 197290.

(10) «La Revolución Francesa y España», en Economía e Ilustración en la España del siglo XVIII. Barcelona, 1981, pp. 139-198.

(11) «Actividades de los franceses en Cádiz (1789-1790)», en Hispania, Madrid, 1959, tomo LXXV, pp. 251-268.

(12) Citado por Lucienne DOMERGUE en: «Las etapas de la propaganda revolucionaria en España» en VV.AA.: «España y la Revolución Francesa». Historia 16, Madrid, 1989, $\mathrm{n}^{\circ} 159$, p. 50. En este artículo cuenta cómo los revolucionarios crearon, en plena frontera, en Bayona y Perpiñán, dos «Comités espagnols d' instruction publique» para centralizar el envío de la propaganda a España.

(13) MARCUELLO, Juan Ignacio: «Las Cortes Generales y Extraordinarias: Organización y poderes para un Gobierno de Asamblea» en: Miguel ARTOLA (ed.): Las Cortes de Cádiz. N 1 de la revista Ayer. Madrid, 1991, p. 103. Precisamente esta influencia francófila será -exagerándola- uno de los argumentos que empleen los escritores reaccionarios para descalificar la primera Constitución española. Vid.: Irene CASTELLS: «La Constitución Gaditana de 1812 y su proyección en los movimientos liberales europeos del primer tercio del siglo XIX», en Trocadero. Revista de Historia Moderna y Contemporánea, $\mathrm{n}^{\circ}$ 1, Cádiz, 1989, pp. 119-120.

(14) Citado por Alberto GIL NOVALES en Las Sociedades Patrióticas. Madrid, 1975, tomo I, p. 392.

(15) Ibídem, capítulo XV, pp. 392-507.

(16) El de la Sociedad o Junta patriótica de Cádiz, por ejemplo, se reproduce completo en DE CASTRO, Adolfo: Historia de Cádiz y su provincia. Cádiz, 1858 (reeditada en 1985). Tomo II, pp. 210-212.

(17) Ibídem.

(18) GIL NOVALES, Alberto: op. cit. Capítulo XIV, pp. 392-507.

(19) CASTELLS, Irene: La utopia insurreccional del liberalismo. Torrijos y las conspiraciones liberales de la década ominosa, Barcelona, 1989, p. 70.

(20) MARICHAL, Carlos: La revolución liberal y los primeros partidos políticos en España, 1834-1844. Madrid, 1980, pp. 84-107. 
(21) JANKE, Peter: Mendizábal y la instauración de la monarquía constitucional en España, 1790-1853. Madrid, 1974, p. 124.

(22) CASTRO, Demetrio: «Orígenes y primeras etapas del republicanismo en España» en TOWNSON, Nigel (ed.): El republicanismo en España (18301977). Madrid, 1994, p. 34. También de D. CASTRO y sobre este período: «Republicanos en armas. Clandestinidad e insurrecionalismo en el reinado de Isabel I» en el Bulletin d' Histoire Contemporaine de l' Espagne. Bordeaux, n²3, 1996, pp. 29-40.

(23) «Jacobinos y populistas. El republicanismo español a mediados del siglo XIX» en ALVAREZ JUNCO, José (comp.), Populismo, caudillaje y discurso demagógico. Madrid, 1987, p. 189.

(24) Tbídem.

(25) TOUCHARD, Jean: Historia de las ideas políticas, Madrid, 1974, p. 361.

(26) SOBOUL, Albert: La Revolución Francesa. Madrid, 1979, p. 211. Distinguía: 1) El primitivo conservador, 2) el de Barnave de 1790, 3) el mixto de 1792 de Brissot y 4) el de 1793.

(27) BOULOISEAU, Marc, La República Jacobina. Nueva historia de la Revolución Francesa. Barcelona, 1980, pp. 44-56. No obstante, el más reciente y completo estado de la cuestión aparece recogido en el libro editado por Luis Roura e Irene Castells: Revolución y democracia. El jacobinismo europeo, Madrid. 1995.

(28) CASTRO, Demetrio: «Influencia en el pensamiento republicano español del siglo XIX» en VV.AA.: «España y la Revolución Francesa». Historia 16. $\mathrm{N}^{\circ}$ 159. Madrid, 1989, p. 63.

(29) ALVAREZ PANTOJA, María José: «La Revolución Francesa en las bibliotecas privadas sevillanas (1800-1868)», en Estudios de Historia Social, nums. 36-37, Madrid, 1986, pp. 55-62. Número monográfico dedicado a la Revolución Francesa y la Península lbérica.

(30) CARO, Diego: Burguesía y jornaleros. Jerez de la Frontera en el sexenio Democrático (1868-1874). Jerez, 1990, pp. 542-545. Los propietarios eran el marqués de Campo Real, Juan Piñero y Miguel de Giles. Esta «galofilia» también ha sido destacada por Jesús A. Martínez en su estudio sobre las bibliotecas nobiliarias del Madrid decimonónico. Vid.: «La cultura nobiliaria: sociabilidad cultural y lecturas de la nobleza en la España del siglo XIX» en: Historia Contemporánea, 1996, n 13-14, pp. 277-279. 
(31) Sobre la historia de El Guadalete: GONGORA, Antonio de: El periodismo jerezano. Apuntes para su historia. Jerez, 1900, pp. 33-36.

(32) CASTRO, Demetrio: «Jacobinos...», p. 208.

(33) La Revolución (24-IX-1868).

(34) Véase, por ejemplo, el artículo publicado por Fernando Garrido en el número 4 de La Revolución.

(35) El Club Democrático (20-X-1868).

(36) Véanse, por citar algunos, los artículos «La educación del pueblo» en $E l$ Club Democrático (20-X-1868), «Enseñanza política» en El Club Democrático (4-XI-1868) y «La educación del pueblo» en El Club y la Revolución (14-XI$1868)$.

(37) El Club Democrático (4-XI-1868).

(38) MORALES, Manuel: «La sociabilidad popular en Málaga, 1840-1874: de la tutela burguesa a la afirmación de una identidad diferenciada», en Estudios de Historia Social, $\mathrm{n}^{\circ}$ 50-51, 1989, p. 261.

(39) ESPIGADO, Gloria: La Primera República en Cádiz. Estructura social y comportamiento político durante 1873. Cádiz, 1993, p. 257.

(40) Ibídem, pp. 258-259.

(41) VOVELLE, Michel: La mentalidad revolucionaria. Barcelona, 1989, pp. 153-161.

(42) HENNESSY, C.A.M.: La República Federal en España. Pi y Margall y el movimiento republicano federal. Madrid, 1966, pp. 99-100.

(43) Ibídem, p. 99.

(44) MENENDEZ, J.: «Un club revolucionario en Granada. Contribución a la metodología de los problemas sociales y políticos de la década de los 70 » en Actas de las I Jornadas de Metodología Aplicada de las Ciencias Históricas. Vigo, 1975, vol. IV, pp. 315-318.

(45) LOPEZ ESTUDILLO, Antonio: Conflictividad social agraria y crisis finisecular. Republicanismo y anarquismo en Andalucía (1868-1900). Tesis doctoral inédita. Barcelona, 1993, p. 18.

(46) Véase $E l$ Club democrático (20-X-1868). 
(47) Se llamaban «El Club Rojo», «Club de la Montaña», «Club de los radicales» o el «Club de la Igualdad». Vid. MORALES, Manuel: «La Gloriosa en Málaga...», p. 401.

(48) El Club Democrático (25-X-1868).

(49) La Revolución de Septiembre (17-X-1868).

(50) La Justicia Social (2-IX-1869) en: LOPEZESTUDILLO, A.: op. cit., p. 17.

(51) Citado por Manuel MORENO en: La Revolución Francesa en la historiografia española del siglo XIX. Sevilla, 1979, p. 61. 